\title{
Study on the Microscale Tensile Properties of Lower Cambrian Niutitang Formation Shale Based on Digital Images
}

\author{
Huailei Song $\mathbb{D}^{1}{ }^{1}$ Zhonghu Wu $\mathbb{D},{ }^{1,2,3}$ Anli Wang, ${ }^{4}$ Wenjibin Sun, ${ }^{5}$ Hao Liu, ${ }^{5}$ Yili Lou, ${ }^{1}$ \\ and Yujun Zuo iD ${ }^{5}$ \\ ${ }^{1}$ College of Civil Engineering, Guizhou University, Guiyang 550025, China \\ ${ }^{2}$ School of Qilu Transportation, Shandong University, Jinan 250002, China \\ ${ }^{3}$ Geotechnical and Structural Engineering Research Center, Shandong University, Jinan 250061, China \\ ${ }^{4}$ Guizhou Province Quality and Safety Traffic Engineering Monitoring and Inspection Center Co., Ltd., Guiyang 550000, China \\ ${ }^{5}$ Mining College, Guizhou University, Guiyang 550025, China
}

Correspondence should be addressed to Zhonghu Wu; wuzhonghugzu@163.com

Received 19 June 2020; Revised 24 October 2020; Accepted 28 November 2020; Published 17 December 2020

Academic Editor: Hualei Zhang

Copyright (c) 2020 Huailei Song et al. This is an open access article distributed under the Creative Commons Attribution License, which permits unrestricted use, distribution, and reproduction in any medium, provided the original work is properly cited.

\begin{abstract}
Tensile strength is an important parameter that affects the initiation and propagation of shale reservoir fractures during hydraulic fracturing. Shale is often filled with minerals such as calcite. To explore the effect of calcite minerals on the tensile strength and failure mode of shale, in this paper, lower Cambrian shale cores were observed by microslice observations and core X-ray whole-rock mineral diffraction analysis, and 7 groups of numerical direct tensile tests were performed on simulated shale samples with different azimuth angles. The test results show that as the azimuth angle $\alpha$ increases, the tensile strength of the samples gradually decreases, and the fracture rate also shows a decreasing trend. The failure modes can be summarized as rootshaped $\left(0^{\circ}\right.$ and $\left.15^{\circ}\right)$, step-shaped $\left(30\right.$ and $\left.45^{\circ}\right)$, fishbone-shaped $\left(60^{\circ}\right)$, and river-shaped $\left(75^{\circ}\right.$ and $\left.90^{\circ}\right)$ fracturing. The smaller the azimuth angle $\alpha$, the easier it is for hydraulic fractures to propagate along the direction of the calcite veins and inhibit the formation of fracture networks in the shale matrix. Considering the correlation between the acoustic emission characteristics and failure mode, the fractal dimension is used to reflect the microscopic failure mode of shale. The larger the fractal dimension, the higher the fracture rate is, the more microcracks exist at the edge of the main crack, the more severe the internal damage is, and the more complex the failure mode of the sample is. As the azimuth angle $\alpha$ increases, the fractal dimension shows a decreasing trend, and the crack becomes smoother. This research has important reference value for the study of hydraulic fracture initiation mechanisms and natural fracture propagation.
\end{abstract}

\section{Introduction}

Shale gas refers to unconventional natural gas stored in dark mud shale or high-carbon-content mud shale reservoirs and often exists in a free or adsorbed form [1-5]. Shale gas is a kind of clean energy. As an effective supplement to conventional energy, it has the advantages of a great resource potential, a wide distribution area, a long exploitation life, and multiple development layers and has gradually become a main focus of global energy development [6-8]. However, shale gas reservoirs have the characteristics of small matrix pore throats, an extremely low permeability, a distinct anisotropy, and an altered formation structure, which makes them extremely dif- ficult to develop [9-13]. Only a very small number of specially developed shale wells that are drilled can be put directly on production, and more than $90 \%$ of wells require manual fracturing and other reservoir modifications to produce high yields $[14,15]$. It is estimated that China's recoverable reserves of shale gas have reached $36.1 \times 10^{12} \mathrm{~m}^{3}$, ranking first in the world, and that mining prospects are vast. The research on shale gas in China started only recently, and the commercial exploitation of shale gas has been realized only in Fuling, Changning, and similar areas. How to realize the large-scale industrialized exploitation of shale gas is of great strategic significance to green economic development and the upgrading of the energy structure in China [16-18]. 
Shale is a typical brittle rock with a tensile strength much lower than its compressive strength [19]. Tensile strength is a key parameter for hydraulic fracturing and an important parameter for fracture initiation and propagation in shale reservoirs with complex natural fractures [20]. The direct tensile method is the most accurate method used to obtain the tensile strength, and it is also the most direct method used to analyse the influence of bedding orientation on the evolution of tensile fractures. The eccentricity problem that cannot be avoided in the direct stretching process makes this test less useful. At present, only Jin et al. [21] have used a dog bone profile sample to directly analyse Marcellus shale to determine the effect of bedding direction on the failure path. When stretching parallel to and perpendicular to bedding, the failure path is perpendicular to the stretching direction. When stretched along a direction inclined to the bedding direction, an inclined failure path easily forms along the bedding. Therefore, indirect tests (Brazilian splitting test) are commonly used to measure the tensile strength of shale.

For a long time, scholars at home and abroad have performed a considerable amount of research on shale mechanical properties and failure modes by performing Brazilian splitting tests. He and Afolagboye [22] systematically studied the effect of weakly laminated surfaces and interlayer bonding forces on shale failure strength and fracture morphology by performing Brazilian splitting tests. Wang et al. [23] studied the anisotropic tensile behaviour of the Longmaxi shale at different strain rates by performing Brazilian splitting tests. Nath and Mokhtari [24] used optical technology and image processing technology to study the relationship between shale tensile strength and the energy required for failure under Brazilian splitting test conditions. Cho et al. [25] studied the anisotropy of shale deformation and strength by performing Brazilian splitting and uniaxial compression tests on shales at different bedding dip angles. Aliabadian et al. [19] studied the effects of moisture content, mineralogy, and stratification on the tensile strength of rich shale by performing Brazilian splitting tests. Vervoort et al. [26] studied the lateral anisotropy of shale by performing Brazilian splitting tests and compared the relationships between the strength change and the final fracture morphology for different weak plane dip angles. Hou et al. [27] conducted Brazilian splitting tests on shale with different bedding dip angles, analysed the changes in absorbed energy during shale failure, and revealed the relationship between bedding angle, tensile strength, $\mathrm{AE}$ energy, and final absorbed energy. Forbes et al. [28] conducted three-point bending tests on Mancos shale, which revealed that regardless of the loading conditions, the fracture of the shale shifted to the plane with the lowest toughness. Chandler et al. [29] studied the effect of bedding orientation on the evolution of tensile crack propagation by performing three-point bending tests. Heng et al. [30] systematically studied the evolution of shale fractures in samples with different bedding orientations under tension by threepoint bending tests and Brazilian splitting tests and discussed the fracture evolution mechanism and bedding direction effect.

Although there are many studies on the tensile strength of layered shale, they mainly focus on macroscale failures such as bedding effects and loading rates. Microscopic research mainly considers the influence of the size effect and prefabricated cracks on the failure mode. There is very limited research on the failure mode of shale filled with minerals such as calcite veins at the microscale. At the same time, the existing microscopic studies have not considered the influence of brittle minerals such as calcite veins and quartz on the heterogeneity of shale, and the fracture process and failure modes at the microscopic scale have not been observed. Therefore, starting from the microstructure of shale, numerical experiments are carried out to accurately determine the tensile strength of shale and to study the fracture process and failure modes of shale at the microscopic scale. This work provides important reference information for research on hydraulic fracture initiation mechanisms.

In this paper, digital image processing technology and $\mathrm{RFPA}^{2 \mathrm{D}}$ systems are combined. By observing the core of the Niutitang Formation shale in Qianbei and analysing the whole rock minerals from core X-ray analysis, it is found that the shale contains a large amount of brittle minerals such as quartz and calcite. Digital image processing technology is used to characterize the shape and spatial distribution of the minerals in this shale, and statistical methods are used to describe the heterogeneity within the shale matrix, quartz, and calcite in the shale. Uniaxial tensile tests on shales with different azimuth angles are conducted using the $\mathrm{RFPA}^{2 \mathrm{D}}$ system. The tensile strength and failure morphology of shale with different azimuth angles are studied in detail. The spatial evolution distribution of the AE energy and the relationship between the fractal dimension and different azimuth angles are investigated. The resulting research findings have important reference value in the further study of the fracture initiation mechanism and the prediction of secondary crack growth and the enhanced recovery factor with shale hydraulic fracturing.

\section{Regional Geological Characteristics}

In this study, the Niutitang Formation shale reservoir in the third block of Fenggang, Guizhou, was selected as the research object. As one of the pilot projects of the national shale gas strategic survey, it provides a good foundation for geological research. The Guizhou strata correspond to the Yangtze stratigraphic zone. According to the characteristics of stratigraphic evolution, the tectonics activity of the northern Guizhou area includes the Xuefeng movement, Caledonian movement, Haixi movement, Indo-Chinese movement, Yanshan movement, and Xishan movement [5]. The superimposition of the multistage tectonic movements during the evolution of these strata has led to the extremely complicated structural morphology in the study area. The tectonic forms formed by the tectonic movement in the three districts of Fenggang are mainly folds and faults that strike north-south and northeast. The folds are dominated by the "slotted" structure striking northeast and north-northeast and develop a series of northeast-oriented complex anticlines and complex synclines. The multiple faults crosscut each other and formed under a complicated tectonic regime. 

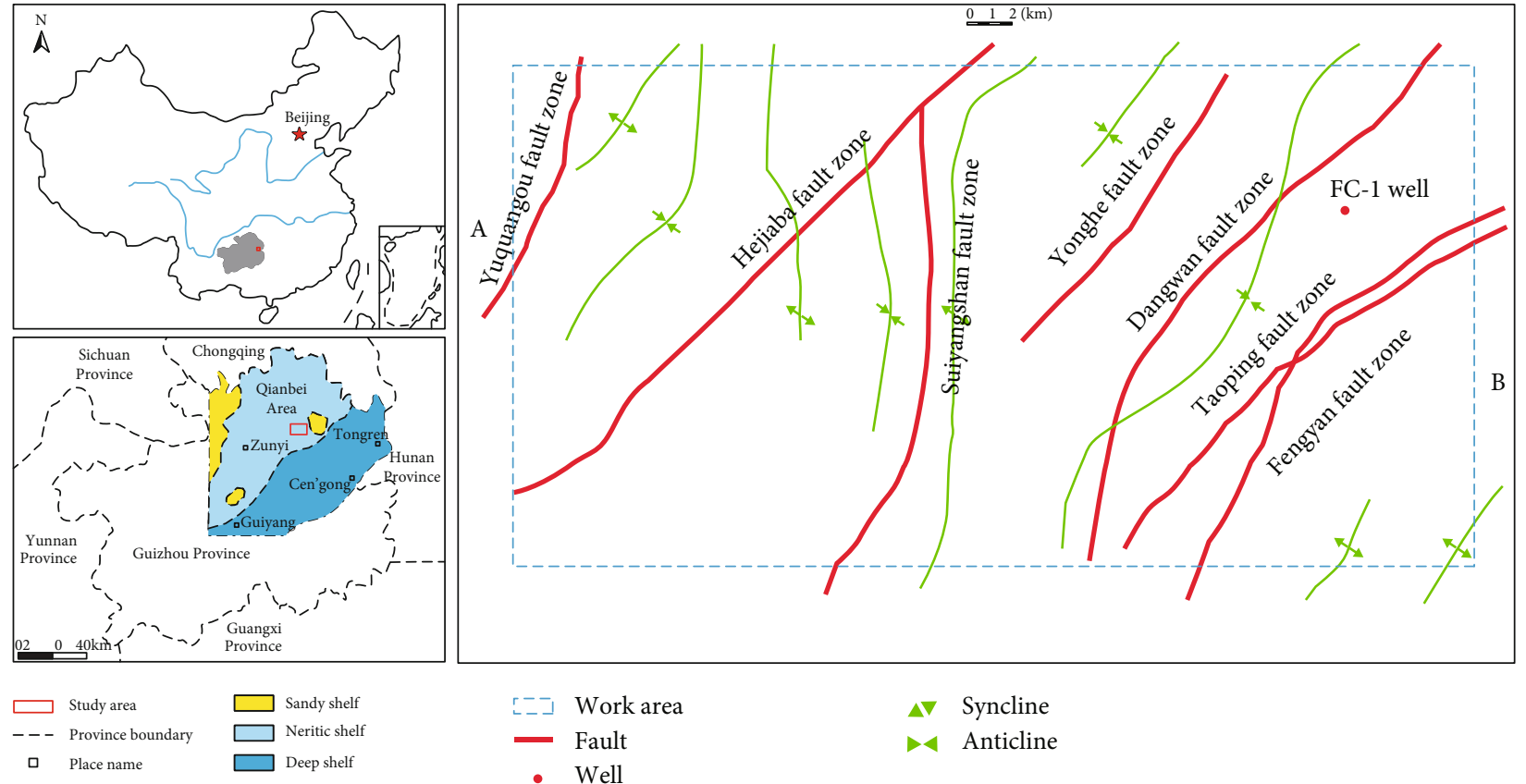

Figure 1: Area map of the third block of Fenggang, Qianbei, Guizhou.

Mainly torsional faults are developed in the northeast and northeast of the study area, as shown in Figure 1 [31].

The Cambrian shale developed in the Niutitang Formation, with shale thicknesses ranging from 80 to $110 \mathrm{~m}$, is mainly siliceous shale and grey-black shale. The total gas volume of Niutitang Formation in the study area is $0.87 \sim 4.13 \mathrm{~m}^{3} / \mathrm{t}$, with an average value of $2.07 \mathrm{~m}^{3} / \mathrm{t}$. Through $\mathrm{X}$-ray diffraction whole-rock quantitative analysis and clay mineral analysis, the lower Cambrian shale reservoir was tested. The test site is that of the Guizhou Coal Field Geology Bureau. In this test, 20 samples of shale from the Niutitang Formation in the lower Cambrian were selected for analysis, with a X'pert Powder instrument. The results show that the average content of quartz is $62.5 \%$ and that the average content of calcite is $7.8 \%$. The crack filling in the study area is mainly calcite. The average content of plagioclase is $15 \%$. The average content of pyrite is $7.4 \%$. The average content of clay minerals is $8 \%$, and the clay is mainly illite, with an average content of $87 \%$. In addition, the sample set also contains a small amount of carbonate minerals, calcite, and dolomite. The black shales of the Niutitang Formation in this area are mainly brittle minerals. The mineral distribution obtained by X-ray diffraction analysis is shown in Figure 2.

\section{Constitutive Relationship of Tensile Element Damage}

Under tensile loading, shale is mainly in the elastic stage, showing obvious brittle characteristics. As the damage continues, the elastic modulus of a shale microunit gradually decreases. Therefore, the constitutive relationship of elastic damage mechanics is suitable for describing the mechanical properties of shale microunits. According to the principle of strain equivalence, it is considered that the strain caused by the stress $\sigma$ acting on the damaged shale is equivalent to the strain caused by the effective stress acting on the undamaged rock. According to this principle, the constitutive relationship of the damaged rock can be obtained through the stress in the undamaged rock $[32,33]$, that is,

$$
\varepsilon=\sigma / E=\sigma /(1-D) E_{0}
$$

where $E$ is the elastic modulus of the shale specimen after damage; $E_{0}$ is the initial elastic modulus of the shale specimen after damage; and $D$ is the damage variable. When $D=0$, the shale sample is in an undamaged state; when $D=1$, the shale sample corresponds to the state of complete damage (fracture or destruction); when $0<D<1$, the damage microunit is irregularly distributed in the rock. In rock samples, the greater $D$ is, the more severe the damage. According to equation (1), when the damage variable $D=1$, the elastic modulus $E=0$, which is inconsistent with the actual damage evolution process of shale. Therefore, a relatively small $E$ of $1.0 \times 10^{-5}$ is generally specified during the test.

In the initial state, the microscopic microunit is viscoelastic, and its mechanical properties can be completely expressed by its elastic modulus and Poisson's ratio. As the stress of the element increases, its strain gradually increases until a certain damage threshold is met, when the element undergoes tensile damage. At the same time, the stretching criterion determines the failure mode. If the microunits meet the stretching criterion, no judgement is made regarding whether the Mohr-Coulomb criterion is satisfied. Whether the Mohr-Coulomb criterion is satisfied is determined in only the microunits that do not meet the stretching criterion. It is assumed that a microunit meets the damage constitutive relationship of elasticity-brittleness and residual strength 


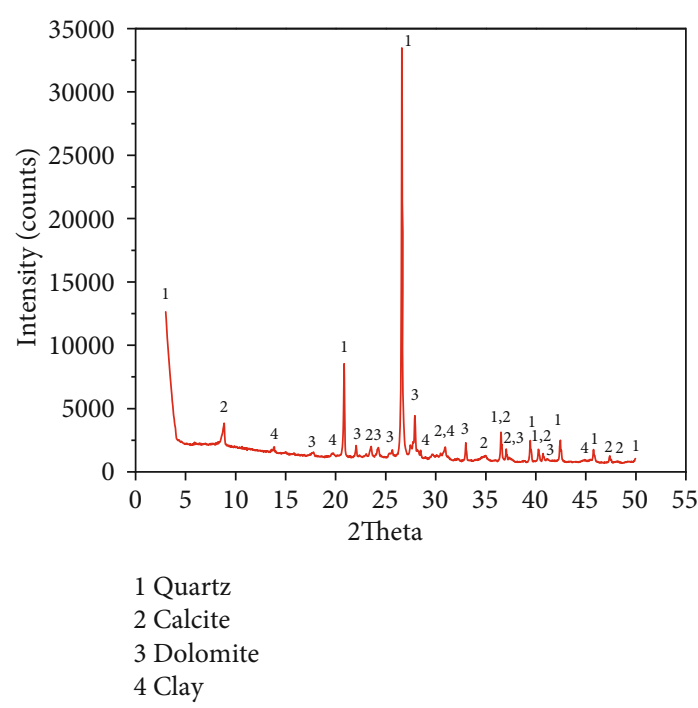

Figure 2: X-ray diffraction analysis of whole rock.

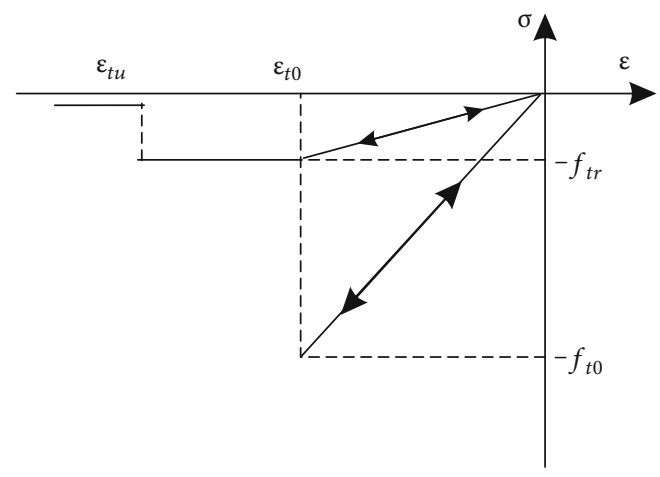

FIGURE 3: Constitutive relationship of elastic damage under uniaxial tension.

under a uniaxial tensile stress state, as shown in Figure 3 [34, 35].

Under uniaxial tension, for the elastic damage constitutive curve given in Figure 3 , the expression of the damage variable is [33]

$$
D= \begin{cases}0, & \varepsilon_{t 0} \leq \varepsilon<0, \\ 1-\frac{f_{t r}}{E_{0} \varepsilon}, & \varepsilon_{t u} \leq \varepsilon<\varepsilon_{t 0}, \\ 1, & \varepsilon \leq \varepsilon_{t u} .\end{cases}
$$

In the formula, $f_{t r}$ is the residual strength of the element; $\varepsilon_{t 0}$ is the tensile strain corresponding to the elastic limit, which is called the tensile damage strain threshold; and $\varepsilon_{t u}$ is the ultimate tensile strain of the element. When the uniaxial tensile strain reaches $\varepsilon_{t 0}$, the element begins to develop tensile damage; when the uniaxial tensile strain reaches $\varepsilon_{t u}$, the element corresponds to the tensile failure state. The relationship between the damage variable $D$ and the effective strain $\varepsilon$ is shown in Figure 4. Under the uniaxial tensile stress state, the definition relation $f_{t r}=\lambda f_{t}=\lambda E_{0} f_{t r} \varepsilon_{t 0}$ holds,

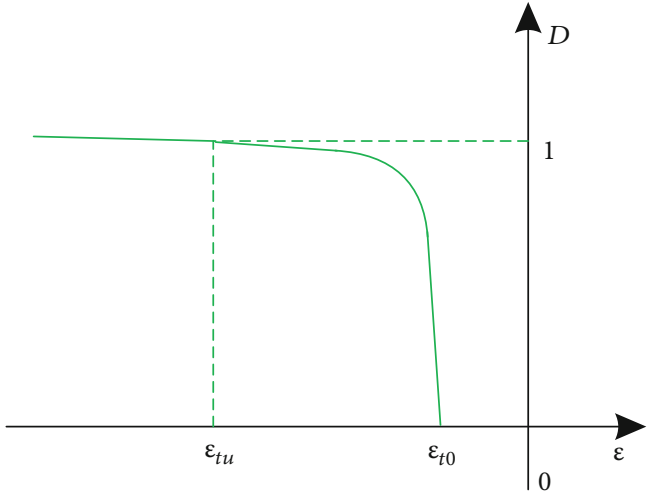

Figure 4: Relationship between damage parameters and effective strain during tensile failure.

where is the uniaxial tensile strength, $\lambda$ is the residual strength coefficient, and $0 \leq \lambda<1$. Therefore, in terms of strain, the damage evolution equation of the microelement under a uniaxial tensile load can be expressed as [32]

$$
D= \begin{cases}0, & \varepsilon>\varepsilon_{t u}, \\ 1-\frac{\lambda \varepsilon_{t 0}}{\varepsilon} \otimes & \varepsilon_{t 0} \leq \varepsilon>\varepsilon_{t u}, \\ 1 \otimes & \varepsilon \leq \varepsilon_{t u} .\end{cases}
$$

\section{Numerical Test}

4.1. Digital Image Characterization of Shale Microstructure. With the continuous development of computer computing capabilities, numerical simulation has made great progress in elucidating the fracture process of rock materials. Digital image processing technology (DIP), as an information resource, essentially converts the research object into a digital image stored in a computer. The image is composed of many pixels and can be regarded as a pixel matrix. This paper uses digital image processing technology to establish a numerical model, map the shale matrix and calcite minerals in the image to a finite element grid, and establish a numerical model that can reflect the microstructure. Shale comprises different minerals, and the colour and brightness of these minerals are significantly different. Therefore, different colours and grey levels can characterize the microstructure of the material. The HSI colour space is selected to segment the image.

The HSI colour space is an intuitive description of colour for the human visual system. Colours are mainly described by hue, saturation, and brightness. The change in the $I$ value is used to obtain the microstructure of different minerals in the rock, and the mechanical analysis of heterogeneous materials is conducted with the RFPA ${ }^{2 \mathrm{D}}$ system. Because the test is performed on a Windows system, the values of each component of the HSI need to be adjusted within the range of 0-255 to convert the RGB colour space.

Figure 5 shows the process of obtaining microsection images of calcite-bearing minerals and quartz minerals in the shale of the Niutitang Formation in the third district of 


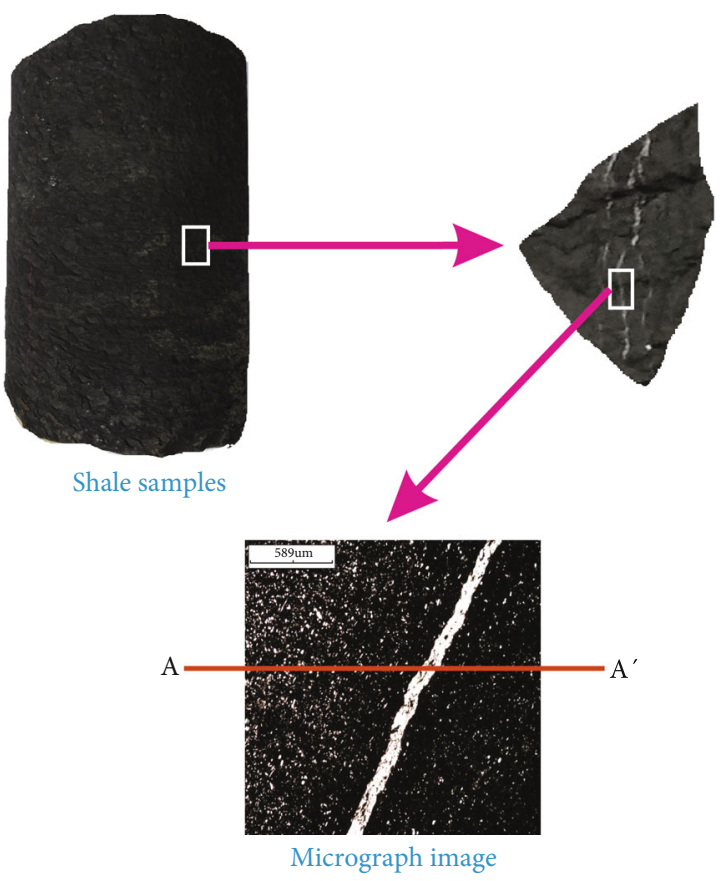

FIgURE 5: Shale microslice image.

Fenggang. The image clearly shows that the calcite veins penetrate the shale: the colours of calcite and quartz are brighter, and the shale is darker. Figure 6 is the change curve of the $I$ value on the AA' scan line based on the obtained shale microslice image. After several experiments, the segmentation thresholds are finally selected as $I=60$ and $I=140$ to segment the image. This segmentation divides the $I$ value into three intervals of $0-60,60-140$, and 140-255. Figure 7 is a digital representation of the microstructure of calcite veins in the shale, which is obtained from digital image processing.

4.2. Establishment of the Numerical Model. In the finite element method, the material area needs to be divided into many small squares. Each pixel in the digital image is regarded as a small square microunit in the finite element grid. For each pixel, the coordinates of the four nodes of the microunit can be converted according to the corresponding vector space position by the proportional relationship between the actual size of the image and the pixel size. The entire image can be converted into a square finite element mesh, and the corresponding material type is assigned in the numerical calculation according to the colour category to which each pixel belongs, thereby introducing the nonuniformity of mathematical image representation into the numerical model.

According to the nature of the rock, the probability distribution density function is used to describe the heterogeneity of the rock. In heterogeneous materials, rocks are divided into many microunits containing different numbers of defects and fissures, each of which has a different strength. Assuming that the local strength obeys a certain probability distribution, the Weibull distribution describes the experimental data of the microdefect distribution in the rock well [36]. Therefore, it is assumed that the elastic modulus and

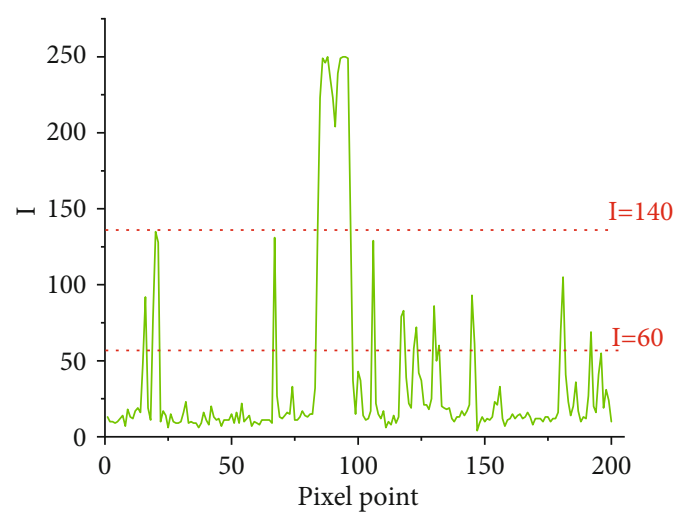

Figure 6: $I$ value change curve on AA' scan line.

strength of the microunits inside the shale and the fracture filling material obey the Weibull distribution:

$$
\varphi(a)=\frac{m}{a_{0}}\left(\frac{a}{a_{0}}\right)^{m-1} \exp \left[-\left(\frac{a}{a_{0}}\right)^{m}\right] .
$$

Here, $\varphi(a)$ is the statistical distribution density of the mechanical properties $a$ of the microunit; $a_{0}$ is the average value of the mechanical properties of the microunit; $a$ is the parameter representing the mechanical properties of the microunit; and $m$ is the uniformity coefficient. In the definition of the Weibull distribution, the parameter $m$ must be greater than 1 . The larger the value of $m$, the closer the property of the material is to uniform, and the more concentrated the mechanical properties in the microscopic microunit are; conversely, the smaller the value of $m$, the more uneven the material is, and the wider the mechanical properties of the microunits are distributed. $m$ is an important parameter that affects the macroscopic response of numerical samples. $m$ and $a_{0}$ must be determined according to the actual macroscopic strength of the rock $[37,38]$. The shale is filled with quartz and penetrated by calcite veins, resulting in nonuniformity. To fully reflect this nonuniformity in the test process, the Monte Carlo method is used to assign values to the finite element grid elements.

Figure 8 is a numerical model obtained by converting an image after digital image processing. The material parameters of the micromedia in the shale are shown in Table 1 [39].

To study the influence of calcite vein filling in the microstructure on the mechanical properties of shale, in the process of numerical image acquisition, a square with a model size of $50 \mathrm{~mm} \times 50 \mathrm{~mm}$ was used, and the centre point of the square was fixed. Rotating clockwise at a $15^{\circ}$ interval, the angle $\alpha$ is investigated, and a total of 7 digital images are acquired, for $0^{\circ}, 15^{\circ}, 30^{\circ}, 45^{\circ}, 60^{\circ}, 75^{\circ}$, and $90^{\circ}$, as shown in Figure 9. During the test, the microstructure is basically consistent among the shale specimens, and the strength characteristics of shale with different azimuth angles are studied via numerical direct tensile tests.

The numerical test loading model is shown in Figure 10. The displacement control loading is used to consider the plane stress problem. The initial value of displacement 


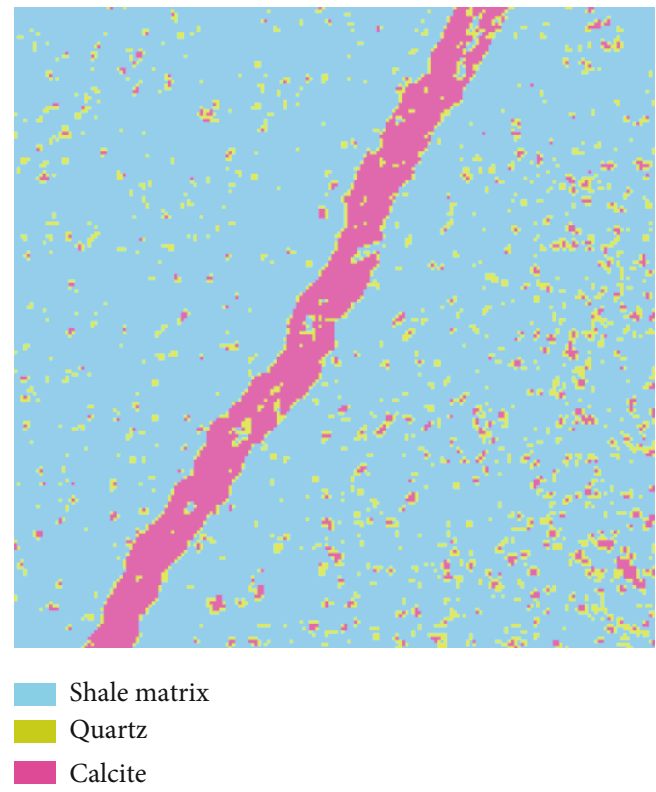

FIGURE 7: Image after threshold segmentation.

loading for the uniaxial tensile test is $-0.0001 \mathrm{~mm}$, the increment of displacement loading at each step is $-0.0002 \mathrm{~mm}$, and the total loading step is 500 steps. Continuous operation is selected when solving. Stress, strain, acoustic emission, AE energy, and cumulative acoustic emission data are collected during the loading process.

\section{Test Results and Discussion}

5.1. Uniaxial Tensile Test Results. According to classical elasticity, the formula for tensile strength can be obtained as

$$
\sigma_{t}=\frac{p}{A}
$$

where $P$ is the maximum load when the pattern is broken and $A$ is the cross-sectional area of the pattern.

Figure 11 is a graph showing the change trend of the stress-strain curve of a shale sample obtained from the test. It can be clearly seen from the figure that the curve increases linearly with the increase in the load, until the specimen breaks down after the peak strength; there is an obvious stress drop, but the specimen retains a residual strength. The whole test process can be divided into two stages: the elastic stage before reaching the peak strength and the brittle failure stage after reaching the peak strength. There is no obvious yield stage, and the specimen clearly shows elastic and brittle failure characteristics. When the $\alpha=0^{\circ}, 15^{\circ}, 30^{\circ}, 45^{\circ}$, and $60^{\circ}$ tests are loaded to the peak strength, the samples suddenly break, showing sudden failure. After reaching the peak strength at $\alpha=75^{\circ}$ and $90^{\circ}$, the stress slowly decreases, showing progressive failure. As the azimuth $\alpha$ increases, the peak strength of the shale sample gradually increases.

Table 2 shows the tensile strength values of the 7 groups of samples. Figure 12 shows the trend of the maximum tensile strength of the 7 groups of tests under different azimuth angles. The curve with the square markers corresponds to the tensile strength, and the curve with the triangle markers corresponds to the elastic modulus.

It can be seen from Figure 12 that the tensile strength of shale gradually decreases with the increase in azimuth angle $\alpha$, and the elastic modulus generally has an inverted " $Z$ "shaped growth trend. This is because the tensile strength of calcite veins is lower than that of the shale. Under the influence of the calcite veins, the tensile strength of shale shows obvious anisotropic characteristics. When $\alpha=0^{\circ}$, because the calcite veins have a greater toughening effect on the overall bearing capacity of the sample, the load on the sample reaches its maximum value, and the maximum tensile strength is $11.693 \mathrm{MPa}$; however, as the azimuth increases, this toughening effect gradually decreases, and the decreasing trend is most obvious within $60 \sim 70^{\circ}$, followed by $15 \sim 45^{\circ}$, and a moderate decreasing trend is observed within $75 \sim 90^{\circ}$. The minimum tensile strength, $9.211 \mathrm{MPa}$, occurs at $90^{\circ}$. The shale strength anisotropy is characterized by the ratio of the tensile strength perpendicular to the direction of the calcite veins to the tensile strength parallel to the direction of the calcite veins. The strength anisotropy is 1.26 . This shows that the direction of the calcite veins has a strong influence on the tensile strength. It is further explained that the degree of bonding between the shale and calcite is weak, and the calcite veins tend to be damaged before the shale matrix. In the process of hydraulic fracturing, the smaller the azimuth angle $\alpha$, the more likely hydraulic fractures will preferentially extend along the calcite veins, inhibiting the formation of complex fracture networks in the shale matrix, thereby reducing the impact on oil and gas production.

Figure 13 shows the damage evolution model and acoustic emission diagram of shale with different azimuths under uniaxial tension. It can be seen from the figure that since the specimen is only subjected to a uniaxial tensile load, the crack is only affected by the tensile effect during the propagation process. The calcite veins form weak surfaces in the structure, and their tensile strength is lower than the tensile strength of the shale matrix. During the loading of the test, the microcracks around the calcite veins expand steadily under the induced tensile stress. The failure mode of shale specimens under uniaxial tension is extremely complicated. When $\alpha=0^{\circ}$ and $\alpha=90^{\circ}$, the crack is generally perpendicular to the loading direction; when $\alpha=30^{\circ}, 45^{\circ}, 60^{\circ}$, and $75^{\circ}$, an inclined fracture path forms; when $\alpha=15^{\circ}, 30^{\circ}$, and $75^{\circ}$, the crack is at an obtuse angle to the loading direction; when $\alpha$ $=45^{\circ}$ and $\alpha=60^{\circ}$, the crack forms an acute angle with the loading direction. This finding can also be reflected in the distribution diagram of the acoustic emission points. When $\alpha=0^{\circ}$, the sample first failed in the shale matrix cemented to the calcite veins, and the fracture penetrated the entire sample along the calcite veins, in the shape of tree roots. When $\alpha=15^{\circ}$, the specimen began to fail from the right end, and the fracture expanded through the calcite vein under tension and continued to expand along the calcite vein until it became unstable and formed a tree root failure. When $\alpha=30^{\circ}$, the specimen started to fail from the left end first and passed through the square solution vein vertically, and the fracture gradually expanded into a step-like failure. When $\alpha$ 


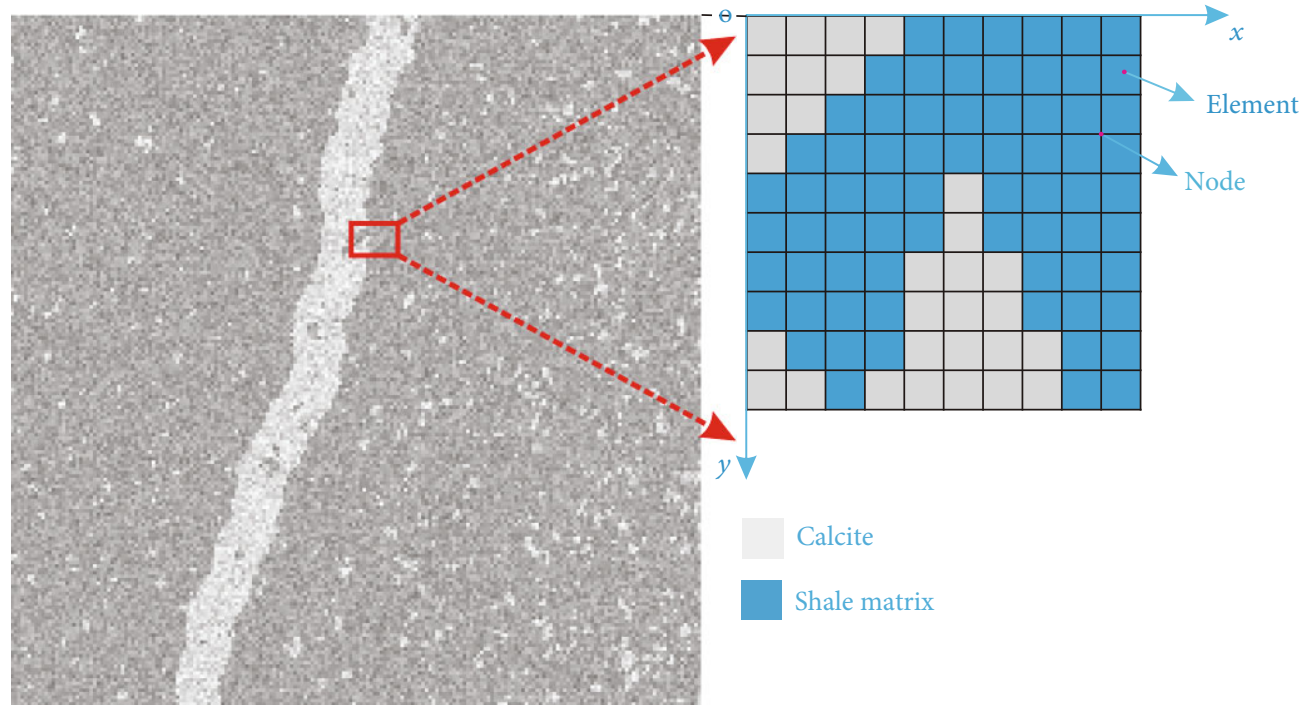

Figure 8: Numerical model and grid after shale transformation.

TABLE 1: Material parameters of shale micromedia [39].

\begin{tabular}{lccccc}
\hline Material & Elastic modulus/GPa & Uniaxial tensile strength/MPa & Pressure rabbi & Poisson's ration $v$ & Frictional angle $\lambda\left({ }^{\circ}\right)$ \\
\hline Shale & 51.6 & 11.67 & 14 & 0.22 & 35 \\
Calcite & 80.5 & 9.00 & 11 & 0.30 & 30 \\
Quartz & 96.0 & 14.00 & 15 & 0.08 & 60 \\
\hline
\end{tabular}

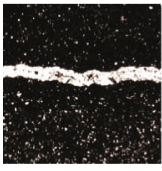

$\alpha=0^{\circ}$

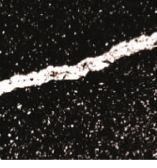

$\alpha=15^{\circ}$

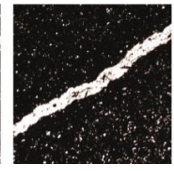

$\alpha=30^{\circ}$

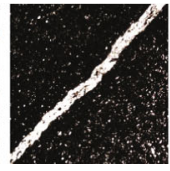

$\alpha=45^{\circ}$

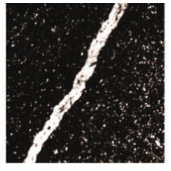

$\alpha=60^{\circ}$

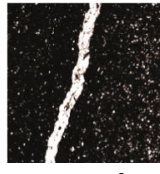

$\alpha=75^{\circ}$

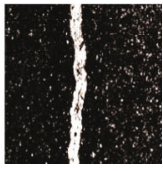

$\alpha=90^{\circ}$

Figure 9: Digital shale images at different azimuths.

$=45^{\circ}, 60^{\circ}, 75^{\circ}$ and $90^{\circ}$, the specimen started to crack from the calcite veins. Specifically, at $45^{\circ}$, two cracks extending through the calcite veins expanded to the left and right ends at the same time and then merge into a step-shaped crack; when $\alpha=60^{\circ}$, the fracture direction was roughly at an angle of $30^{\circ}$ with the calcite vein, and the fracture eventually expanded into a fish-bone failure; when $\alpha=75^{\circ}$, three fractures appeared simultaneously in the calcite vein, but only one fracture eventually penetrated the specimen, gradually expanding into a river-shaped failure; when $\alpha=90^{\circ}$, calcite veins first appeared as arc-shaped microfractures and quickly expanded to river-shaped fractures at both ends under tensile action. In summary, due to the significant influence of calcite veins on the shale failure mode, the failure modes of direct stretching of shale can be divided into root-shaped $\left(0^{\circ}\right.$ and $\left.15^{\circ}\right)$, step-shaped $\left(30\right.$ and $\left.45^{\circ}\right)$, fishbone-shaped $\left(60^{\circ}\right)$, and river-shaped $\left(75^{\circ}\right.$ and $\left.90^{\circ}\right)$ fracturing.

Figure 14 is the trend graph of the fracture rate of shale samples under different azimuth angles. The fracture rate is the ratio of the fracture area to the sample area. Table 3 shows the fracture rate and cumulative acoustic emission statistics at different azimuth angles. The specific process is as follows:
(1) automatic segmentation of the image using PCAS software to obtain a binary map. (2) Smoothing the edges of the fracture and removing the noise to obtain the fracture skeleton diagram, as shown in Figure 11. (3) The software automatically analyses the relevant information of the fractures, and the fracture rate of the fractures can be obtained. Additionally, the relevant data can be saved. It can be seen from the figure that the fracture rate is the largest at $15^{\circ}$, corresponding to the largest fracture area in each group of samples and the most severe microfracturing around the main fracture, internal damage, and macrodamage. With the decrease in the azimuth angle, the fracture rate gradually decreases. At $90^{\circ}$, the fracture rate is the smallest, the fracture area is the smallest, the main fracture is relatively smooth, and the damage is relatively gentle. The variation trend of the fracture rate is generally consistent with the cumulative acoustic emission value.

5.2. Acoustic Emission Results and Analysis. The spatial sequence characteristics of acoustic emission refer to the elastic waves emitted by the rapid release of local energy under loading. It is an effective tool for studying the evolution 


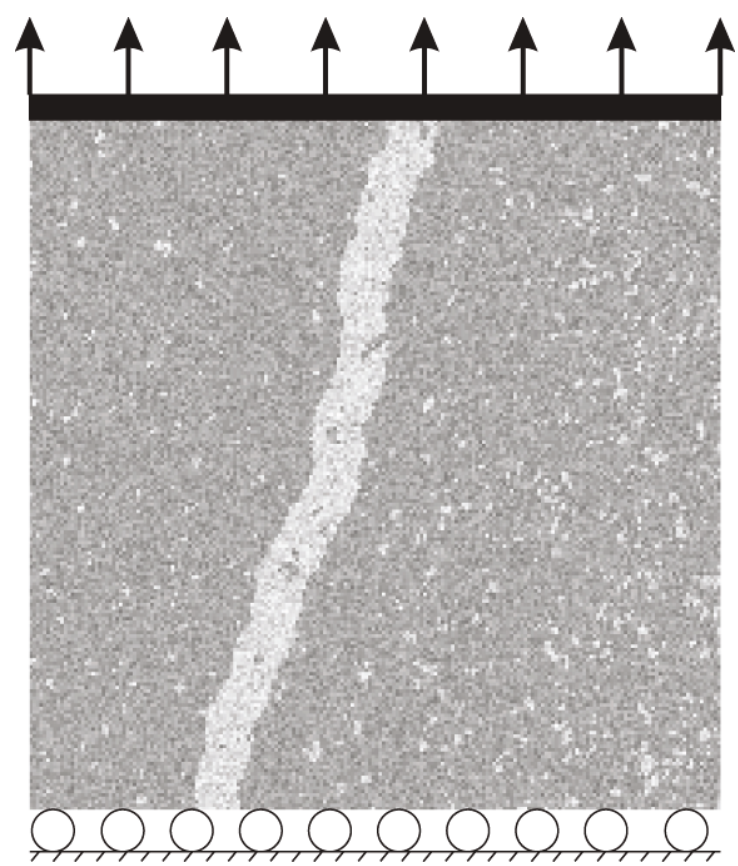

Figure 10: Model loading diagram.

process of internal damage in rocks. The analysis of the spatial distribution of acoustic emission can reflect the initiation and evolution of internal fractures in rocks. In $\mathrm{RFPA}^{2 \mathrm{D}}$, the failure of a sample microunit will release the elastic energy stored during the deformation process. It is assumed that the occurrence of an acoustic event represents the failure of a microunit. Therefore, by recording the number of damage microunits and related energy release in a specimen, $\mathrm{RFPA}^{2 \mathrm{D}}$ can simulate acoustic emission (AE) activity [40].

In the acoustic emission map, each point of the spatial distribution represents the location of a corresponding rupture signal from a failure microunit. The yellow part in the figure indicates microunits with tensile damage generated by the current loading step, and the black part indicates the microunits with full failure. It can be clearly seen from the acoustic emission diagram that the macroscopic failure mode of the specimen during uniaxial stretching is only a combination of damage microunits caused by tensile failure. This is because the sample will only generate tensile stress in the vertical direction under the uniaxial tensile load; the tensile stress concentration area is first formed on a weak surface of the internal structure of the sample, and a calcite vein is a weak surface of this structure. Microunit damage occurs first under this action. When $\alpha=0^{\circ}, 15^{\circ}, 30^{\circ}, 45^{\circ}$, and $60^{\circ}$, the yellow part of the acoustic emission diagram is tightly connected. When $\alpha=75^{\circ}$ and $90^{\circ}$, there is a tiny black damage microunit at the calcite vein. This is because of the influence of calcite veins on shale anisotropy under different azimuth angles, and the toughening effect of calcite veins on the whole sample decreases with the increase in $\alpha$. When the tensile strength reaches the peak, a part of the elastic energy is released first, causing the calcite veins to break before the shale matrix. This is also the reason for the progressive failure of the $75^{\circ}$ and $90^{\circ}$ specimens. The application of the acoustic emission phenomenon shows that the microfailure process of the shale is consistent with the Griffith failure condition. During the loading process of brittle rock material, stress concentration easily occurs at the end of the microfracture, and then the brittle rock material is continuously damaged and fails. When the tensile strength is exceeded, microcracks begin to propagate until they penetrate the material [41]. Based on the spatial distribution characteristics of acoustic emission, it is known that the damage evolution process of the microunits in the sample reflects the macrofailure mode well.

5.3. Fractal Characteristics of the Shale Microfailure Process. Fractal theory is a tool used to describe irregular and complex objects that widely exist in nature, such as mountains, trees, and clouds. Unlike traditional Euclidean geometry, fractal theory holds that different spatial dimensions can be either discrete or continuous. Self-similarity is the basic property of fractals and can be quantified by fractal dimension [4244]. The emergence of fractal theory has provided new ideas for solving some complex problems. The damage evolution of rock is essentially the accumulation and release of energy inside the rock. The moment the rock fails under the load, the stored energy of the deformation process is quickly released in the form of elastic waves. This phenomenon is called acoustic emission. Xie [45] combined fractal with rock mechanics and confirmed that there is self-similarity in the process of rock material failure and damage, which conforms to the fractal feature. Each microrupture in the process of rock failure evolution corresponds to an acoustic emission event. Therefore, acoustic emission has fractal characteristics. By analysing the fractal characteristics of the spatial distribution of acoustic emission during rock damage and destruction, it is concluded that the fractal dimension value can reflect the failure mode of the rock [46].

There are many different fractal dimension definitions, including the information dimension $D_{i}$, correlation dimension $D_{g}$, capacity dimension $D_{C}$, Lyapunov dimension $D_{L}$, and box-counting dimension $D_{S}$. The calculation of the box-counting dimension is simple and is the most widely used method in the calculation of fractal dimensions. In this paper, the fractal dimension of the acoustic emission map of the uniaxial tensile test is calculated using the self-similar dimension. In this paper, by writing a fractal dimension program on the MATLAB software platform, the acoustic emission graphs under different stress levels obtained by uniaxial tensile testing are binarized, and a calculation program is imported to obtain the fractal dimension of the acoustic emission graph. The formula is defined as

$$
D_{s}=-\lim _{r \rightarrow 0} \frac{\log N(r)}{\log r},
$$

where $D_{S}$ is the self-similar fractal dimension of the damage area; $r$ is the side length of the square box; and $N(r)$ is the number of boxes required to cover the destruction area in the entire figure with a square box with side length $r$.

Figure 15 shows the fitting curve of the fractal characteristics of the shale damage evolution area with an azimuth 


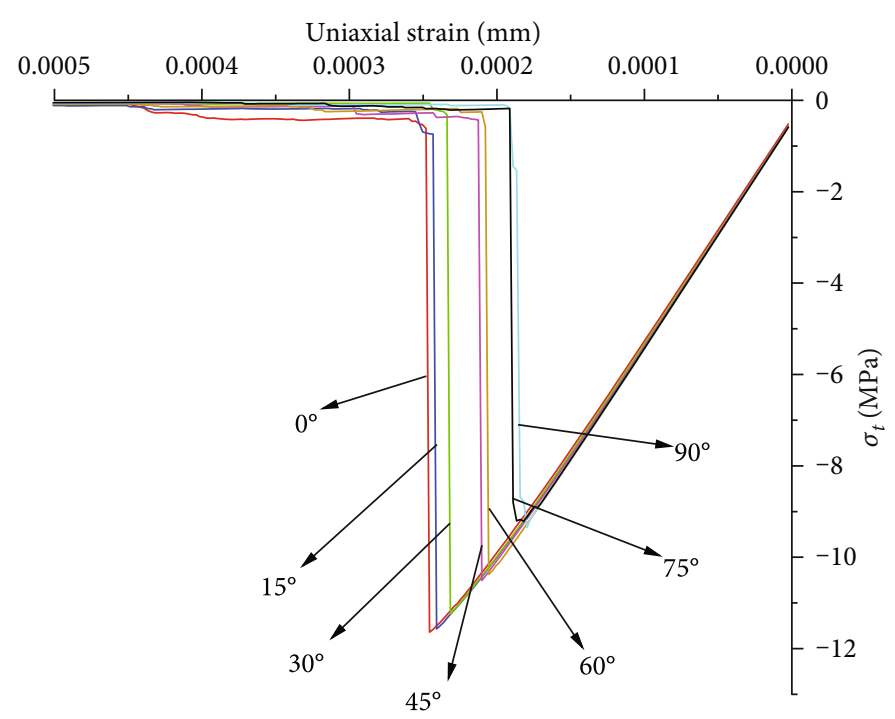

FIGURE 11: Stress-strain diagrams at different azimuth angles.

TABLE 2: Elastic modulus and uniaxial tensile strength of shale.

\begin{tabular}{lcc}
\hline $\begin{array}{l}\text { Azimuth } \\
\mathrm{a} /\left(^{\circ}\right)\end{array}$ & $\begin{array}{c}\text { Elastic } \\
\text { modulus/GPa }\end{array}$ & $\begin{array}{c}\text { Uniaxial tensile } \\
\text { strength/MPa }\end{array}$ \\
\hline 0 & 45.63 & 11.639 \\
15 & 48.02 & 11.570 \\
30 & 48.54 & 11.283 \\
45 & 49.98 & 10.507 \\
60 & 50.47 & 10.370 \\
75 & 51.53 & 9.250 \\
90 & 50.64 & 9.211 \\
\hline
\end{tabular}

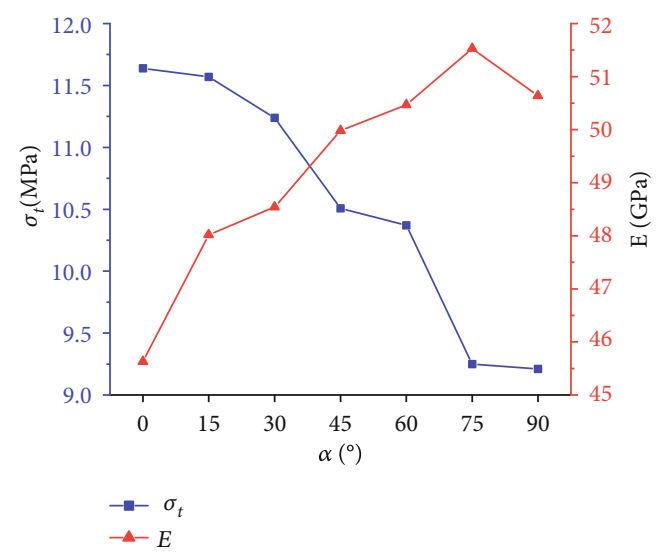

FIgURE 12: Trend of tensile strength and elastic modulus of shale under different azimuth angles.

angle of $90^{\circ}$ when the stress level is $100 \%$, and the fractal dimension is $D_{S}=1.354$.

Figures 16-18 show the trends of the fractal dimensions, $\mathrm{AE}$ energy, azimuth, and stress levels, respectively. Table 4 lists the fractal dimension values and acoustic emission energy values of 7 groups of samples with different azimuth angles. In Figure 16, the AE energy and stress levels show a parabolic growth trend. When the stress level is less than $30 \%$, the AE energy of each group of shale samples is basically 0 in a silent period, and there is almost no energy released during this stage. When the stress level is between $30 \%$ and $70 \%$, the AE energy increase for each group of shale samples is relatively moderate. This stage is a relaxation period, but the growth rates of the $0^{\circ}, 15^{\circ}$, and $30^{\circ}$ groups are significantly higher than those of the other 4 groups. When the stress level exceeds $80 \%$, the microunit damage in the shale sample intensifies, the AE energy rises sharply, and it is in the active period. The azimuth angle and $\mathrm{AE}$ energy have a negative correlation. The $\mathrm{AE}$ energy of the $0^{\circ}$ and $15^{\circ}$ samples increases the fastest, and the change trends of the two groups of samples are very close. The $15^{\circ}$ sample has the largest $\mathrm{AE}$ energy, followed by the $0^{\circ}$ sample. The $90^{\circ}$ sample has the smallest $\mathrm{AE}$ energy. This shows that the $15^{\circ}$ specimen undergoes the largest energy release due to the fracture and damage formation under the tensile load, corresponding to the most severe internal microdamage, and the most severe macrofailure mode. It can be seen from the figure that as the azimuth increases, the AE energy of the sample decreases. It is further proven from the perspective of energy release that the presence of the calcite veins has a significant effect on the shale anisotropy.

Figure 17 shows that during the test, as the internal tensile damage of the shale sample continues to accumulate, the fractal dimension and stress level show a logarithmic curve growth trend. When the stress level is between $20 \%$ and $50 \%$, the fractal dimension increases the fastest. When the stress level is less than $20 \%$, there is no damaged microunit in the shale sample, and the fractal dimension is 0 . When the stress level reaches $20 \%$, the damaged microunits are irregularly distributed in the sample, and the fractal dimension of the sample at $60^{\circ}$ begins; when the stress level reaches $30 \%$, the $0^{\circ}, 15^{\circ}, 30^{\circ}$, and $45^{\circ}$ samples gradually exhibit nonzero fractal dimensions. The final fractal dimension at $75^{\circ}$ and $90^{\circ}$ was reached after the stress level reached $40 \%$; when the stress level exceeded $50 \%$, as the stress level increased, the growth trend of the fractal dimension was relatively gentle, 


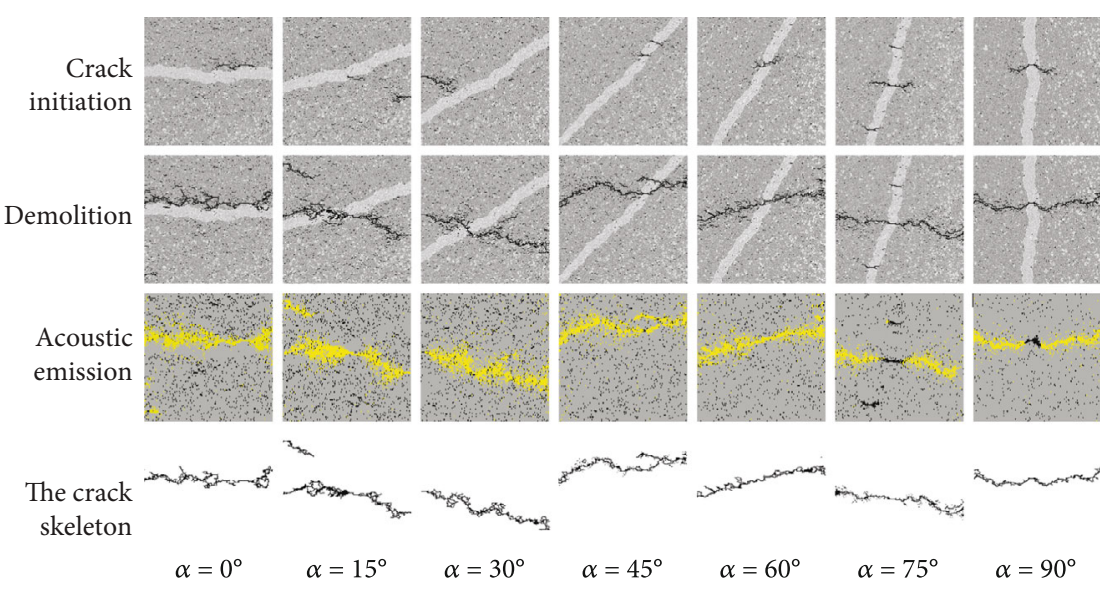

Figure 13: Uniaxial tensile damage evolution of shale under different azimuth angles.

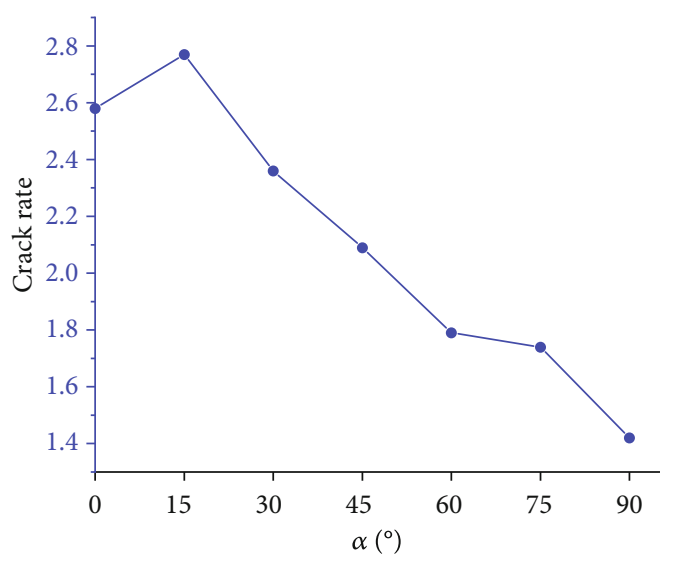

FIgURE 14: Relationship between fracture rate and cumulative acoustic emission of samples under different azimuth angles

TABLE 3: Statistics of fracture rate and cumulative acoustic emission at different angles.

\begin{tabular}{lc}
\hline$\alpha\left(^{\circ}\right)$ & Crack rate/\% \\
\hline $0^{\circ}$ & 2.58 \\
$15^{\circ}$ & 2.77 \\
$30^{\circ}$ & 2.36 \\
$45^{\circ}$ & 2.09 \\
$60^{\circ}$ & 1.79 \\
$75^{\circ}$ & 1.74 \\
$90^{\circ}$ & 1.42 \\
\hline
\end{tabular}

and the growth trend of the fractal dimension of the specimens at all angles was approximately the same. When the azimuth angle was $15^{\circ}$, the fractal dimension of the sample reached the maximum. The fractal dimension of the remaining groups gradually decreased with increasing azimuth angle. At $90^{\circ}$, the fractal dimension was the smallest. The change law of the fractal dimension and the AE energy changes are consistent. According to the above results, during the stretching process, the larger the azimuth angle, the less likely it is that element damage and damage will occur in the shale samples. Under tensile stress, when the calcite

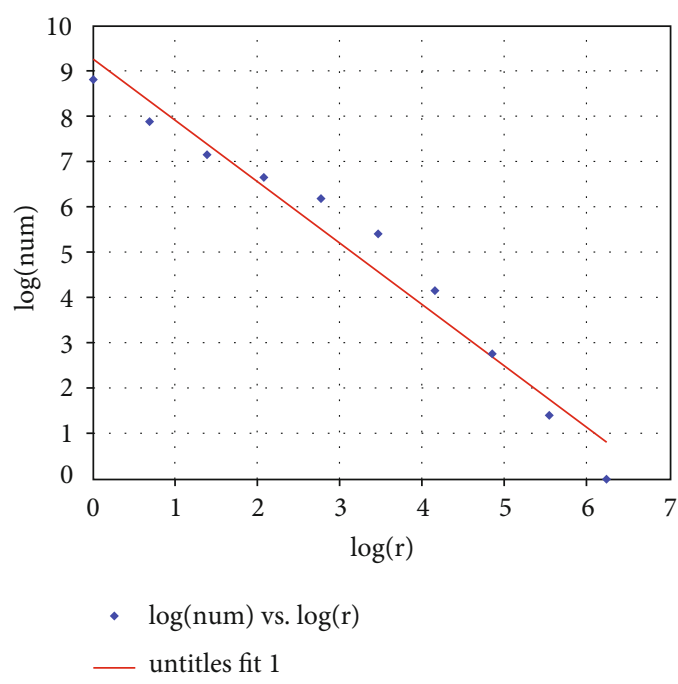

FIgURE 15: Fitting curve of the fractal characteristics of the damaged area at a stress level of $100 \%$ and an azimuth angle of $90^{\circ}$.

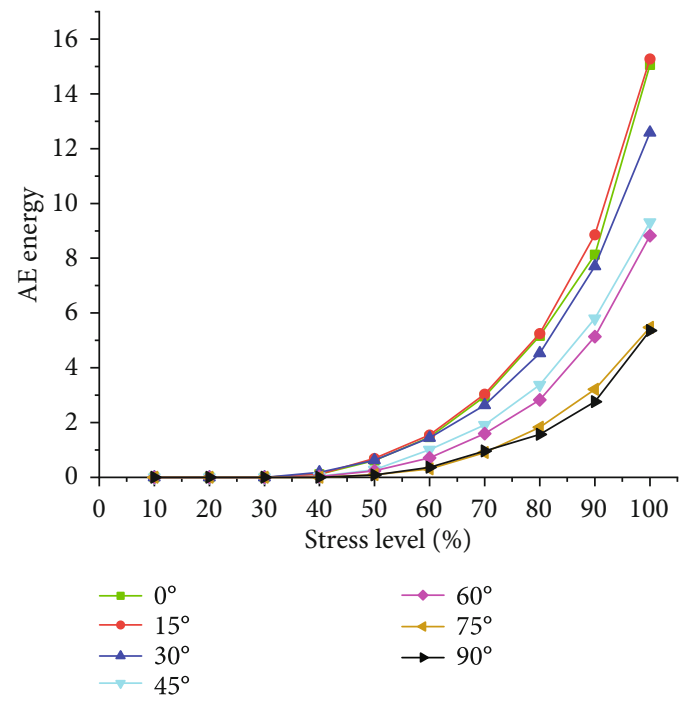

FIgURE 16: Relationship between stress levels and AE energy at different azimuth angles. 


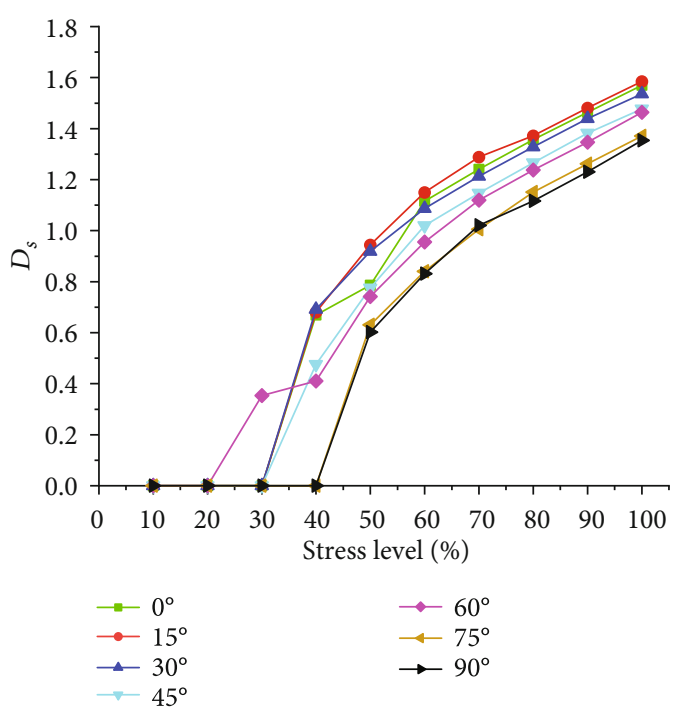

Figure 17: Relationship between stress levels and fractal dimensions at different azimuth angles.

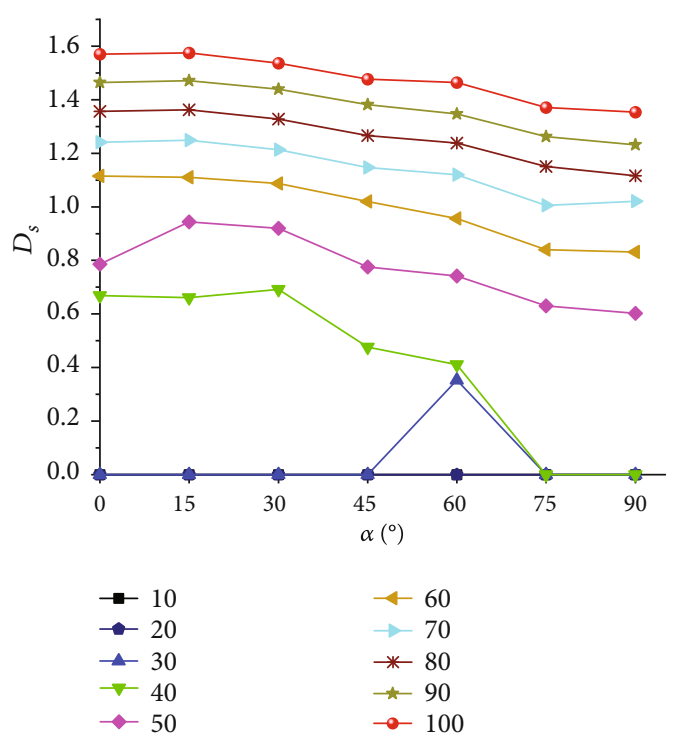

FIGURE 18: Relationship between position angle and fractal dimension under different stress levels.

veins and the shale matrix are subjected to tensile stress together, microcracks do not easily form, but independent calcite veins or shale matrix easily form microcracks under tension.

Figure 18 shows the relationship curve between the fractal dimension and the azimuth angle. The abscissa represents the azimuth angle, and the ordinate represents the fractal dimension. In general, the curve trend is roughly decreasing. When the stress level reaches $100 \%$, the $15^{\circ}$ specimen has the largest fractal dimension and the $90^{\circ}$ specimen has the smallest, $D_{S}=1.575$ and $D_{S}=1.354$, respectively. Further analysis of the reasons for this result shows that the failure path of the $90^{\circ}$ specimen is smooth, the failure form is simple, the fracture rate is low, and there are few microfractures around the main crack, so the fractal dimension is small. The failure path of the $15^{\circ}$ sample is fragmented, and crack terminations within the sample are common. The failure mode is complex, with the highest fracture rate. There are a large number of microcracks around the main crack, and the fractal dimension $D_{S}$ reaches the maximum. There are many microfractures around the main fracture, so the fractal dimension is relatively large. For the macrofailure mode, the larger the fractal dimension is, the more complicated the failure, the wider the fracture propagation area, and the more severe the internal damage. Conversely, the smaller the fracture is, the smoother the fracture, the smaller the fracture area, and the weaker the internal damage. The results described above are depicted in a three-dimensional coordinate system, as shown in Figure 19, and the change trend between the three parameters can be clearly seen. The effect of calcite veins with different azimuth angles on the shale failure mode was confirmed from the fractal perspective.

\section{Conclusion}

(1) The calcite veins have a significant influence on the tensile strength of the shale samples. As the azimuth angle $\alpha$ increases, the shale tensile strength increases, and the tensile strength reaches the maximum value of $11.639 \mathrm{MPa}$ at $15^{\circ}$. The tensile strength at $90^{\circ}$ is the smallest, which is $9.211 \mathrm{MPa}$. The ratio of the tensile strength perpendicular to the direction of the calcite veins to that along the direction of the calcite veins is 1.26 . The calcite veins at different angles have different toughening effects on shale. Shale and calcite veins have the greatest toughening effect when they are subjected to tensile stress at the same time

(2) Shale samples are affected by the morphology and uneven arrangement of quartz minerals and calcite veins. The failure modes can be classified into four types: tree root-shaped $\left(0^{\circ}\right.$ and $\left.15^{\circ}\right)$, step-shaped (30 and $\left.45^{\circ}\right)$, fishbone-shaped $\left(60^{\circ}\right)$, and river-shaped $\left(75^{\circ}\right.$ and $\left.90^{\circ}\right)$ fracturing. As the azimuth angle $\alpha$ increases, the ratio of the area occupied by the crack to the sample area, that is, the fracture rate, gradually decreases. The reason for this result is that, on the one hand, during the evolution of the rock's geological history, the uneven arrangement of quartz mineral particles that are stronger than the shale matrix causes the cracks to turn and expand, while on the other hand, the calcite veins are weak surfaces in the shale structure, where the degree of cementation is weaker and microcracks are more likely to develop. In the process of the hydraulic fracturing of shale reservoirs, the greater the angle between the loading direction and the calcite veins, the more likely the hydraulic fractures will extend along the calcite veins, suppressing the formation of complex fracture networks in the shale matrix

(3) The release of elastic waves inside the rock is directly related to the generation (damage) of microcracks 
TABLE 4: AE energy and fractal dimension values.

\begin{tabular}{|c|c|c|c|c|c|c|c|c|c|c|}
\hline $\begin{array}{l}\text { Stress level } \\
\alpha\end{array}$ & $10 \%$ & $20 \%$ & $30 \%$ & $40 \%$ & $50 \%$ & $60 \%$ & $70 \%$ & $80 \%$ & $90 \%$ & $100 \%$ \\
\hline $0^{\circ} \mathrm{AE}$ & 0 & 0 & 0 & 0.12 & 0.62 & 1.47 & 2.95 & 5.17 & 8.13 & 15.06 \\
\hline $\mathrm{D}$ & 0 & 0 & 0 & 0.6691 & 0.7865 & 1.115 & 1.241 & 1.357 & 1.464 & 1.57 \\
\hline $15^{\circ} \mathrm{AE}$ & 0 & 0 & 0 & 0.12 & 0.69 & 1.55 & 3.04 & 5.25 & 8.86 & 15.28 \\
\hline $\mathrm{D}$ & 0 & 0 & 0 & 0.6806 & 0.944 & 1.15 & 1.289 & 1.3721 & 1.481 & 1.585 \\
\hline $30^{\circ} \mathrm{AE}$ & 0 & 0 & 0 & 0.18 & 0.63 & 1.44 & 2.64 & 4.53 & 7.71 & 12.58 \\
\hline $\mathrm{D}$ & 0 & 0 & 0 & 0.692 & 0.9193 & 1.087 & 1.2133 & 1.328 & 1.4391 & 1.536 \\
\hline $45^{\circ} \mathrm{AE}$ & 0 & 0 & 0 & 0.04 & 0.28 & 1.01 & 1.91 & 3.38 & 5.8 & 9.31 \\
\hline $\mathrm{D}$ & 0 & 0 & 0 & 0.4758 & 0.7755 & 1.02 & 1.1472 & 1.266 & 1.382 & 1.477 \\
\hline $60^{\circ} \mathrm{AE}$ & 0 & 0 & 0 & 0.03 & 0.24 & 0.71 & 1.6 & 2.83 & 5.14 & 8.82 \\
\hline $\mathrm{D}$ & 0 & 0 & 0.3531 & 0.4108 & 0.7413 & 0.9559 & 1.122 & 1.238 & 1.347 & 1.464 \\
\hline $75^{\circ} \mathrm{AE}$ & 0 & 0 & 0 & 0 & 0.1 & 0.31 & 0.9 & 1.83 & 3.21 & 5.47 \\
\hline $\mathrm{D}$ & 0 & 0 & 0 & 0 & 0.6303 & 0.8403 & 1.005 & 1.151 & 1.262 & 1.371 \\
\hline $90^{\circ} \mathrm{AE}$ & 0 & 0 & 0 & 0 & 0.09 & 0.37 & 0.96 & 1.57 & 2.76 & 5.36 \\
\hline $\mathrm{D}$ & 0 & 0 & 0 & 0 & 0.602 & 0.8315 & 1.021 & 1.116 & 1.231 & 1.354 \\
\hline
\end{tabular}

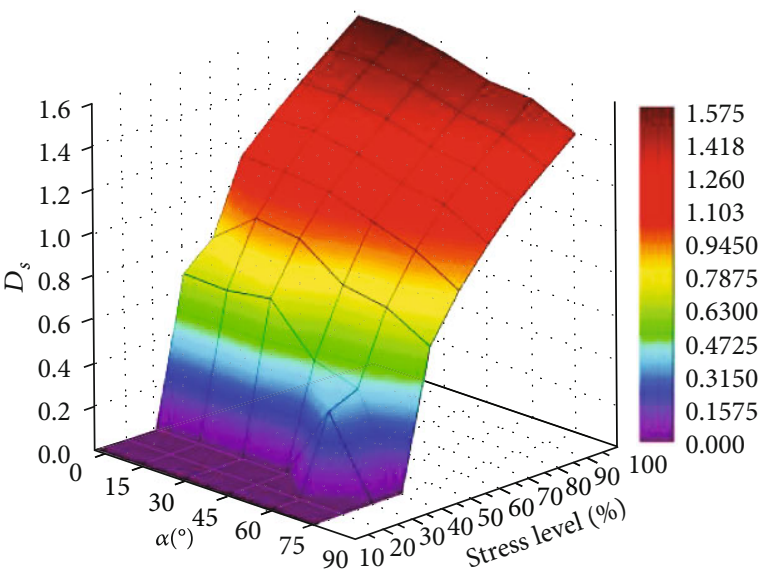

Figure 19: Relationship between stress level, azimuth, and fractal dimension.

inside the rock. The spatial distribution characteristics of acoustic emission points are clearly connected to the failure modes of the shale samples. Qualitatively, the location of microfractures inside shale samples and the development trend of cracks are described during the entire failure evolution process. The AE energy and stress levels show a parabolic growth trend, which can be roughly divided into three stages: the silent period, relaxation period, and active period. When $\alpha=15^{\circ}$, the $\mathrm{AE}$ energy is the largest. As the azimuth angle $\alpha$ increases, the $\mathrm{AE}$ energy gradually decreases. When the calcite veins and the shale matrix both bear the tensile stress, microcracks do not easily initiate. Independently, calcite veins or shale matrix are prone to microcracking under tensile stress

(4) The distribution of acoustic emission points closely corresponds to the macroscopic damage evolution process. Based on fractal theory, the fractal dimen- sions under different azimuth angles exhibit very significant differences. When the stress level reaches the peak stress, the fractal dimension of the $15^{\circ}$ sample is the largest, and that of the $90^{\circ}$ sample is the smallest, $D_{s}=1.575$ and $D_{s}=1.354$, respectively. When $\alpha=$ $15^{\circ}$, the sample fracture rate is nearly the maximum, the sample failure mode is complex, there are many microcracks at the edge of the main crack, and the internal damage is severe. As the azimuth angle $\alpha$ increases, the fractal dimension shows a decreasing trend, the fracture rate also decreases, and the main crack becomes smoother. The fractal dimension can effectively characterize the failure characteristics of shale. The fractal dimension can quantitatively characterize the complexity of shale fractures, revealing that the larger the calcite vein dip angle is, the simpler the shale failure mode

\section{Data Availability}

The data used to support the study is available within the article.

\section{Conflicts of Interest}

The authors declare that they have no conflicts of interest.

\section{Acknowledgments}

This study was supported by the Project of Special Fund for Science and Technology of Water Resources Department of Guizhou Province (Project No. KT201804), Guizhou Science and Technology Fund (Project No. [2020]4Y046, Project No. [2019]1075, and Project No. [2018]1107), the National Natural Science Foundation of China (Project Nos. 51964007 and 51774101), the High-Level Innovative Talents Training Project in Guizhou Province (Project No. 2016-4011), Project of Scientific Research Project of Guiyang Rail Transit 
Line 2 Phase I Project (Project No. D2(I)-FW-YJ-2019-001WT), and Teaching reform project of Guizhou University (Project No. JG201990).

\section{References}

[1] C. R. Clarkson, N. Solano, R. M. Bustin et al., "Pore structure characterization of North American shale gas reservoirs using USANS/SANS, gas adsorption, and mercury intrusion," Fuel, vol. 103, pp. 606-616, 2013.

[2] Q. Zhou, X. Xiao, H. Tian, and L. Pan, "Modeling free gas content of the Lower Paleozoic shales in the Weiyuan area of the Sichuan Basin, China," Marine and Petroleum Geology, vol. 56, pp. 87-96, 2014.

[3] T. Guo, S. Zhang, Z. Qu, T. Zhou, Y. Xiao, and J. Gao, "Experimental study of hydraulic fracturing for shale by stimulated reservoir volume," Fuel, vol. 128, pp. 373-380, 2014.

[4] C. Han, Z. Jiang, M. Han, M. Wu, and W. Lin, "The lithofacies and reservoir characteristics of the Upper Ordovician and Lower Silurian black shale in the Southern Sichuan Basin and its periphery, China," Marine and Petroleum Geology, vol. 75, pp. 181-191, 2016.

[5] L. Li, B. Huang, Y. Li, R. Hu, and X. Li, "Multi-scale modeling of shale laminas and fracture networks in the Yanchang formation, Southern Ordos Basin, China," Engineering Geology, vol. 243, pp. 231-240, 2018.

[6] Y. Zeng, Q. Wang, Z. Ning, and H. Sun, "A mathematical pressure transient analysis model for multiple fractured horizontal wells in shale gas reservoirs," Geofluids, vol. 2018, Article ID 8065949, 16 pages, 2018.

[7] A. Lisjak, G. Grasselli, and T. Vietor, "Continuum-discontinuum analysis of failure mechanisms around unsupported circular excavations in anisotropic clay shales," International Journal of Rock Mechanics and Mining Sciences, vol. 65, pp. 96-115, 2014.

[8] R. Wang, Z. Hu, C. Sun et al., "Comparative analysis of shale reservoir characteristics in the Wufeng-Longmaxi (O3w-S1l) and Niutitang $(€ 1 \mathrm{n})$ Formations: a case study of wells JY1 and TX1 in the southeastern Sichuan Basin and its neighboring areas, southwestern China," Interpretation, vol. 6, no. 4, pp. SN31-SN45, 2018.

[9] Z. Wu, Y. Zuo, S. Wang, J. Sunwen, and L. Liu, "Experimental study on the stress sensitivity and influence factors of shale under varying stress," Shock and Vibration, vol. 2018, Article ID 3616942, 9 pages, 2018.

[10] Y. Yang and M. Zoback, "Viscoplastic deformation of the Bakken and adjacent formations and its relation to hydraulic fracture growth," Rock Mechanics and Rock Engineering, vol. 49, no. 2, pp. 689-698, 2016.

[11] W. Ju and W. Sun, "Tectonic fractures in the Lower Cretaceous Xiagou Formation of Qingxi Oilfield, Jiuxi Basin, NW China. Part two: numerical simulation of tectonic stress field and prediction of tectonic fractures," Journal of Petroleum Science and Engineering, vol. 146, pp. 626-636, 2016.

[12] Y. Wang, Y. Zhu, S. Chen, and W. Li, "Characteristics of the nanoscale pore structure in Northwestern Hunan shale gas reservoirs using field emission scanning electron microscopy, high-pressure mercury intrusion, and gas adsorption," Energy \& Fuels, vol. 28, no. 2, pp. 945-955, 2014.

[13] D. J. K. Ross and R. M. Bustin, "The importance of shale composition and pore structure upon gas storage potential of shale gas reservoirs," Marine and Petroleum Geology, vol. 26, no. 6, pp. 916-927, 2009.

[14] B. Mahanta, A. Tripathy, V. Vishal, T. N. Singh, and P. G. Ranjith, "Effects of strain rate on fracture toughness and energy release rate of gas shales," Engineering Geology, vol. 218, pp. 39-49, 2017.

[15] K. Zhang, Z. Jiang, X. Xie et al., "Lateral percolation and its effect on shale gas accumulation on the basis of complex tectonic background," Geofluids, vol. 2018, Article ID 5195469, 11 pages, 2018.

[16] Z. Wu, Y. Zuo, S. Wang et al., "Numerical simulation and fractal analysis of mesoscopic scale failure in shale using digital images," Journal of Petroleum Science and Engineering, vol. 145, pp. 592-599, 2016.

[17] R. Wang, Z. Hu, S. Long et al., "Differential characteristics of the upper Ordovician-lower Silurian Wufeng-Longmaxi shale reservoir and its implications for exploration and development of shale gas in/around the Sichuan Basin," Acta Geologica Sinica-English Edition, vol. 93, no. 3, pp. 520-535, 2019.

[18] Y. Lou, Z. Wu, W. Sun et al., "Study on failure models and fractal characteristics of shale under seepage-stress coupling," Energy Science \& Engineering, vol. 8, no. 5, pp. 1634-1649, 2020.

[19] Z. Aliabadian, G.-F. Zhao, and A. R. Russell, "Failure, crack initiation and the tensile strength of transversely isotropic rock using the Brazilian test," International Journal of Rock Mechanics and Mining Sciences, vol. 122, article 104073, 2019.

[20] H. Li, B. Lai, H.-H. Liu, J. Zhang, and D. Georgi, "Experimental investigation on Brazilian tensile strength of organic-rich gas shale," SPE Journal, vol. 22, no. 1, pp. 148-161, 2017.

[21] Z. Jin, W. Li, C. Jin, J. Hambleton, and G. Cusatis, "Anisotropic elastic, strength, and fracture properties of Marcellus shale," International Journal of Rock Mechanics and Mining Sciences, vol. 109, pp. 124-137, 2018.

[22] J. He and L. O. Afolagboye, "Influence of layer orientation and interlayer bonding force on the mechanical behavior of shale under Brazilian test conditions," Acta Mechanica Sinica, vol. 34, no. 2, pp. 349-358, 2018.

[23] Y. Wang, C. Li, Y. Hu, and T. Mao, "Brazilian test for tensile failure of anisotropic shale under different strain rates at quasi-static loading," Energies, vol. 10, no. 9, p. 1324, 2017.

[24] F. Nath and M. Mokhtari, "Optical visualization of strain development and fracture propagation in laminated rocks," Journal of Petroleum Science and Engineering, vol. 167, pp. 354-365, 2018.

[25] J.-W. Cho, H. Kim, S. Jeon, and K.-B. Min, "Deformation and strength anisotropy of Asan gneiss, Boryeong shale, and Yeoncheon schist," International Journal of Rock Mechanics and Mining Sciences, vol. 50, pp. 158-169, 2012.

[26] A. Vervoort, K.-B. Min, H. Konietzky et al., "Failure of transversely isotropic rock under Brazilian test conditions," International Journal of Rock Mechanics and Mining Sciences, vol. 70, pp. 343-352, 2014.

[27] P. Hou, F. Gao, Y. U. Yang, Z. Zhang, and X. Zhang, "Effect of bedding orientation on failure of black shale under Brazilian tests and energy analysis," Chinese Journal of Geotechnical Engineering, vol. 38, no. 5, pp. 930-937, 2016.

[28] N. D. Forbes Inskip, P. G. Meredith, M. R. Chandler, and A. Gudmundsson, "Fracture properties of Nash Point shale as a function of orientation to bedding," Journal of Geophysical Research: Solid Earth, vol. 123, no. 10, pp. 8428-8444, 2018. 
[29] M. R. Chandler, P. G. Meredith, N. Brantut, and B. R. Crawford, "Fracture toughness anisotropy in shale," Journal of Geophysical Research: Solid Earth, vol. 121, no. 3, pp. 1706-1729, 2016.

[30] S. Heng, X. Liu, X. Z. Li, X. Zhang, and C. Yang, "Study on the fracture propagation mechanisms of shale under tension," Chinese Journal of Rock Mechanics and Engineering, vol. 38, no. 10, pp. 2031-2044, 2019.

[31] Z. Wu, Y. Zuo, S. Wang et al., "Numerical study of multiperiod palaeotectonic stress fields in Lower Cambrian shale reservoirs and the prediction of fractures distribution: a case study of the Niutitang Formation in Feng'gang no. 3 block, South China," Marine and Petroleum Geology, vol. 80, pp. 369-381, 2017.

[32] W. C. Zhu and C. A. Tang, "Numerical simulation of Brazilian disk rock failure under static and dynamic loading," International Journal of Rock Mechanics and Mining Sciences, vol. 43, no. 2, pp. 236-252, 2006.

[33] C. A. Tang, A. A. G. Webb, W. B. Moore, Y. Y. Wang, T. H. $\mathrm{Ma}$, and T. T. Chen, "Breaking Earth's shell into a global plate network," Nature Communications, vol. 11, no. 1, p. 3621, 2020.

[34] Y. Xu, W. Yao, and K. Xia, "Numerical study on tensile failures of heterogeneous rocks," Journal of Rock Mechanics and Geotechnical Engineering, vol. 12, no. 1, pp. 50-58, 2020.

[35] W. C. Zhu, J. Liu, C. A. Tang, X. D. Zhao, and B. H. Brady, "Simulation of progressive fracturing processes around underground excavations under biaxial compression," Tunnelling and Underground Space Technology, vol. 20, no. 3, pp. 231247, 2005.

[36] X. Huang, S. B. Tang, and C. A. Tang, "Boundary-effect and scale-heating rate equivalence effect of cracking behavior in the rock models subjected to heating from the central borehole," Science China Technological Sciences, vol. 63, no. 5, pp. 809-818, 2020.

[37] W. C. Zhu and C. A. Tang, "Numerical simulation on shear fracture process of concrete using mesoscopic mechanical model," Construction and Building Materials, vol. 16, no. 8, pp. 453-463, 2002.

[38] C. A. Tang, H. Y. Liu, W. C. Zhu et al., "Numerical approach to particle breakage under different loading conditions," Powder Technology, vol. 143-144, pp. 130-143, 2004.

[39] Z. Wu, Y. Lou, S. Yin et al., "Acoustic and fractal analyses of the mechanical properties and fracture modes of bedding-containing shale under different seepage pressures," Energy Science \& Engineering, vol. 8, no. 10, pp. 3638-3656, 2020.

[40] C. A. Tang, X. H. Xu, S. Q. Kou, P.-A. Lindqvist, and H. Y. Liu, "Numerical investigation of particle breakage as applied to mechanical crushing -Part I: single-particle breakage," International Journal of Rock Mechanics and Mining Sciences, vol. 38, no. 8, pp. 1147-1162, 2001.

[41] F. W. J. Wu and S. Qi, "Phenomena and theoretical analysis for the failure of brittle rocks," Journal of Rock Mechanics and Geotechnical Engineering, vol. 2, no. 4, pp. 331-337, 2010.

[42] J. Li, Q. Du, and C. Sun, “An improved box-counting method for image fractal dimension estimation," Pattern Recognition, vol. 42, no. 11, pp. 2460-2469, 2009.

[43] R. Zhang, F. Dai, M. Z. Gao, N. W. Xu, and C. P. Zhang, "Fractal analysis of acoustic emission during uniaxial and triaxial loading of rock," International Journal of Rock Mechanics and Mining Sciences, vol. 79, pp. 241-249, 2015.
[44] S. W. Zhang, K. J. Shou, X. F. Xian, J. P. Zhou, and G. J. Liu, "Fractal characteristics and acoustic emission of anisotropic shale in Brazilian tests," Tunnelling and Underground Space Technology, vol. 71, pp. 298-308, 2018.

[45] H. P. Xie, An Introduction to Fractal - Rock Mechanics, Science Press, Beijing, China, 1996.

[46] H. P. Xie, J. F. Liu, Y. Ju, J. Li, and L. Z. Xie, "Fractal property of spatial distribution of acoustic emissions during the failure process of bedded rock salt," International Journal of Rock Mechanics and Mining Sciences, vol. 48, no. 8, pp. 13441351, 2011. 